\title{
Cana-de-açúcar tratada com óxido de cálcio fornecida com diferentes níveis de concentrado para novilhas de corte em confinamento ${ }^{1}$
}

\author{
Kamila Andreatta Kling de Moraes ${ }^{2}$, Sebastião de Campos Valadares Filho ${ }^{3}$, Eduardo \\ Henrique Bevitori Kling de Moraes ${ }^{2}$, Maria Ignez Leão ${ }^{3}$, Rilene Ferreira Diniz Valadares ${ }^{4}$, \\ Odilon Gomes Pereira ${ }^{3}$, Bárbara Pena Soléro ${ }^{5}$
}

\footnotetext{
1 Projeto financiado pela FAPEMIG e pelo CNPq.

2 Programa de Pós-graduação em Zootecnia - UFV.

${ }^{3}$ Departamento de Zootecnia - UFV.

${ }^{4}$ Departamento de Medicina Veterinária - UFV.

${ }^{5}$ Curso de Graduação em Zootecnia - UFV.
}

RESUMO - Objetivou-se avaliar o desempenho, a digestibilidade aparente total; a eficiência síntese microbiana e o balanço de nitrogênio $(\mathrm{BN})$ de novilhas de corte em confinamento alimentadas com dietas à base de cana-de-açúcar tratada ou não com óxido de cálcio (CaO, 1\%) e diversos níveis de concentrado (NC). Utilizaram-se 24 animais, com 177,0 kg PC médio inicial e 8-12 meses de idade, distribuídos em delineamento inteiramente casualizado em esquema fatorial $2 \times 3$, cana-de-açúcar in natura e cana-de-açúcar tratada ou não com 1,0\% CaO e três NC (0,0;0,5 e 1,0\% PC). Não houve interação volumoso $\times$ nível de NC para o consumo dos nutrientes. Com exceção da FDN, a dieta à base de cana-de-açúcar tratada com CaO prejudicou o consumo dos nutrientes (em kg/dia e em \% PC). Apenas o consumo de FDN não foi afetado pelo nível de NC. O consumo dos demais nutrientes apresentou comportamento linear positivo com o aumento do NC. Não foram observados efeitos do tratamento da cana-de-açúcar com $\mathrm{CaO}$ e da interação volumoso $\times$ NC sobre a digestibilidade dos nutrientes, que, com exceção da FDN, aumentou de acordo com o NC das dietas. O fluxo de $\mathrm{N}$ microbiano e os teores de $\mathrm{N}$ uréico no soro foram menores nos animais que consumiram cana-de-açúcar tratada com CaO. A eficiência de síntese microbiana, cujo valor médio foi de 12,10 gPBmic/kg NDT, não foi influenciada pela cana-de-açúcar tratada com CaO nem pelo NC. A cana-de-açúcar tratada com $\mathrm{CaO}$ reduziu o ganho médio diário, que aumentou conforme o NC. A cana-de-açúcar tratada com $1 \%$ CaO e fornecida após 24 horas de armazenamento prejudica o consumo da maioria dos nutrientes, o que piora o desempenho animal, enquanto o oferecimento de concentrado no nível de até 1,0\% PC melhora o desempenho animal.

Palavras-chave: consumo, desempenho, digestibilidade, hidrólise

\section{Sugarcane treated with calcium oxide and different concentrate levels for feedlot beef heifers}

\begin{abstract}
This research was carried out to evaluate the performance, total apparent digestibility, efficiency of microbial synthesis, nitrogen balance $(\mathrm{NB})$ of crossbreed Holstein $\times$ Zebu heifers fed sugarcane treated or not with calcium oxide $(\mathrm{CaO}-1.0 \%)$ and different concentrate levels (CL), in feedlot. A total of 24 animals with initial average $177.0 \mathrm{~kg}$ BW and 8-12 months old was allotted to a complete randomized design with a $2 \times 3$ factorial arrangement, sugarcane in nature and sugarcane treated or not with $1.0 \% \mathrm{CaO}$ and three CL $(0.0,0.5$ and $1.0 \% \mathrm{BW})$. No interaction between forage and CL for nutrients intake was observed. Except for NDF intake, diet based in sugarcane treated with CaO reduced the nutrients intake ( $\mathrm{kg} /$ day and \% BW). Only the NDF intake was unaffected by CL, the other nutrients showed a positive linearly behavior as $\mathrm{CL}$ increased. No effects of the treatment of sugarcane with $\mathrm{CaO}$ and interaction between forage and CL on nutrient digestibilities were observed, except for NDF that increased with the CL in the diets. The microbial $\mathrm{N}$ and $\mathrm{N}$ urea content in serum was smaller in animals that were fed sugarcane treated with $\mathrm{CaO}$. The efficiency of microbial synthesis, with mean value of $12.10 \mathrm{gCPmic} / 100 \mathrm{~g}$ TDN, was unaffected by the sugarcane treated with $\mathrm{CaO}$ to and nor by CL. Sugarcane treated with CaO reduced the average daily gain, which increased with the CL. Sugarcane treated with $1.0 \% \mathrm{CaO}$, fed after 24 hours of storage, prejudice most of nutrient intakes and worse the animal performance, while the concentrate offer levels up to $1.0 \%$ BW improve animal performance.
\end{abstract}

Key Words: digestibility, hydrolyze, intake, performance 


\section{Introdução}

Entre os recursos forrageiros alternativos para minimização dos efeitos prejudiciais da entressafra das pastagens, a cana-de-açúcar se destaca na alimentação de ruminantes, pois possibilita a obtenção de melhores desempenhos produtivos e econômicos. Entretanto, existem limitações quanto ao consumo dessa forragem, principalmente em virtude do baixo teor de compostos nitrogenados (N) e de alguns minerais, assim como da baixa digestibilidade dos componentes da parede celular (Mendonça et al., 2004).

Uma alternativa para melhor utilização da cana-deaçúcar seria o aumento do nível de concentrado na dieta ou o desenvolvimento de tratamentos que promovam o rompimento da estrutura da fração fibrosa para torná-la mais digestível (Burgi, 1985, citado por Ezequiel et al., 2005). Recentemente, pesquisas com o óxido de cálcio $(\mathrm{CaO})$ têm se destacado e seu uso para o tratamento hidrolítico da cana-de-açúcar se baseia na formação de hidróxido de cálcio $\left(\mathrm{Ca}(\mathrm{OH})_{2}\right)$, que, segundo Berger et al. (1994), é um agente alcalino com moderado poder de hidrólise da fibra.

Segundo Silva et al. (2005), a digestibilidade da matéria seca (MS) do bagaço de cana-de-açúcar aumentou de 30 para $60 \%$ com a aplicação de 100 litros de solução com 3\% de $\mathrm{CaO}$ para cada $125 \mathrm{~kg}$ de bagaço, após 48 horas do tratamento. Oliveira et al. (2006), ao avaliarem a hidrólise da cana-de-açúcar com dois níveis (0,5 e 1,0\%) de CaO, verificaram que, com o aumento do nível de $\mathrm{CaO}$, o pH da canade-açúcar aumentou provocando redução dos teores de FDN, MO e PB.

De acordo com Santos et al. (2005), a única vantagem da adição de $\mathrm{CaO}$ à cana-de-açúcar é a possibilidade de seu armazenamento na forma picada, uma vez que ocorrem perdas de MS tanto na cana-de-açúcar in natura quanto na cana tratada com $\mathrm{CaO}$. Essa perda é menor na cana-deaçúcar tratada com 1,0 ou 1,5\% de CaO e armazenada por até dez dias.

Neste estudo, objetivou-se avaliar o efeito do fornecimento de cana-de-açúcar in natura adicionada de $1 \%$ de $\mathrm{CaO}$ e armazenada por 24 horas sobre os consumos, as digestibilidades totais aparente dos nutrientes, a síntese microbiana e o ganho de peso de novilhas de corte recebendo diferentes níveis de concentrado.

\section{Material e Métodos}

O experimento foi realizado no Laboratório de Animais do Departamento de Zootecnia da Universidade Federal de Viçosa. A fase de campo foi realizada entre os meses de agosto e novembro de 2005. Foram utilizadas 24 novilhas (Nelore e mestiças Nelore-Holandês) com peso corporal (PC) médio inicial de $177,0 \mathrm{~kg}$ e 8 a 12 meses de idade, confinadas em baias individuais providas de comedouro e bebedouro e com área total de $30,0 \mathrm{~m}^{2}\left(8,0 \mathrm{~m}^{2}\right.$ cobertos com telhas de amianto). Os animais foram pesados, identificados e vermifugados no início do experimento e mantidos por 14 dias em período de adaptação à dieta experimental e às instalações.

Durante o período de adaptação, a dieta foi fornecida à vontade, duas vezes ao dia (de manhã e à tarde), e o consumo foi medido diariamente. Após esse período, os animais foram pesados novamente, após 12 horas de jejum de sólidos, sorteados e distribuídos em baias individuais de acordo com os tratamentos. O experimento teve duração de 84 dias, divididos em três períodos de 28 dias. O peso corporal (PC) dos animais foi utilizado para o ajuste da quantidade de concentrado fornecida no período seguinte, uma vez que o concentrado foi ajustado de acordo com o PC dos animais.

Avaliou-se o efeito do fornecimento da cana-de-açúcar in natura adicionada ou não de $1,0 \%$ de $\mathrm{CaO}$ e associada a três níveis de concentrado ( 0,0 ; 0,5 e 1,0\% PC). A cana-deaçúcar com $\mathrm{CaO}$ foi fornecida à vontade após 24 horas de armazenamento, corrigida com 1,0\% da mistura uréia/sulfato de amônia (9:1) na base da matéria natural. A cana-deaçúcar in natura foi oferecida imediatamente após a trituração e também foi corrigida com 1,0\% da mistura uréia/ sulfato de amônia (9:1) na base da matéria natural. Os concentrados foram formulados para as dietas conterem aproximadamente $13 \%$ de PB (Tabela 1 ).

Após o cálculo da quantidade de $\mathrm{CaO}$, procedeu-se à distribuição e à mistura da cana-de-açúcar até a completa homogeneização. Em seguida, o volumoso foi amontoado para sua posterior utilização. Para o tratamento da cana, utilizou-se 1,0\% de cal virgem micropulverizada na base da matéria natural do volumoso, sem diluir em água, uma vez que não há necessidade de se dissolver a cal na água, pois a cana possui quantidade de água suficiente para que ocorra a hidratação do $\mathrm{CaO}$, ou seja, precisa-se de 1,0 mol de $\mathrm{H}_{2} \mathrm{O}$ para cada mol de $\mathrm{CaO}$ para a formação do hidróxido de cálcio $\left(\mathrm{Ca}(\mathrm{OH})_{2}\right)$, assim, para cada 56,0 g de cal são necessários 18,0 g de água.

Os alimentos foram fornecidos à vontade (Tabela 2), duas vezes ao dia, e ajustados de forma a manter as sobras em torno de 5 a 10\% do fornecido, com água permanentemente à disposição dos animais. Os animais que não receberam concentrado tiveram livre acesso à mistura mineral. A quantidade de ração fornecida foi registrada diariamente. 
Tabela 1 - Composição dos concentrados (\%MN)

\begin{tabular}{lcc}
\hline Ingrediente (\%) & \multicolumn{2}{c}{ Nível de concentrado $(\% \mathrm{PV})$} \\
\cline { 2 - 3 } & 0,5 & 1,0 \\
\hline Farelo de soja & 21,54 & 13,74 \\
Fubá de milho & 73,86 & 83,76 \\
Calcário $^{\text {Mistura mineral }}{ }^{1}$ & 1,20 & 0,80 \\
\hline
\end{tabular}

${ }^{1}$ Composição: $50 \% \mathrm{NaCl}$ e $50 \%$ de Fosbovi 40 (garantia/kg: Ca - $240 \mathrm{~g}$, $\mathrm{P}-174 \mathrm{~g}, \mathrm{Mg}-2.000 \mathrm{mg}$, Co $-100 \mathrm{mg}, \mathrm{Cu}-1.250 \mathrm{mg}$, Fe $-1.795 \mathrm{mg}$,

I - $90 \mathrm{mg}$, Se - $15 \mathrm{~g}, \mathrm{Zn}-5.270 \mathrm{mg}$, veículo q.s.p. - $1.000 \mathrm{~g}$ )

Tabela 2 - Composição química da cana-de-açúcar e dos concentrados (\%MS)

\begin{tabular}{lrrrrr}
\hline Item & \multicolumn{2}{c}{ Concentrado $(\% \mathrm{PV})$} & & \multicolumn{2}{c}{ Cana-de-açúcar ${ }^{1}$} \\
\cline { 2 - 3 } \cline { 6 - 6 } & \multicolumn{1}{c}{0,5} & 1,0 & & Sem CaO & Com CaO \\
\hline MS & 89,64 & 90,17 & & 27,77 & 27,40 \\
$\mathrm{MO}^{2}$ & 92,32 & 94,82 & & 94,52 & 88,63 \\
$\mathrm{~PB}^{2}$ & 16,65 & 13,81 & & 14,18 & 13,66 \\
$\mathrm{EE}^{2}$ & 2,99 & 3,17 & & 1,91 & 1,92 \\
$\mathrm{FDN}^{2}$ & 10,17 & 10,10 & & 47,45 & 49,19 \\
$\mathrm{FDNi}^{2}$ & 1,73 & 1,83 & & 25,03 & 27,27 \\
$\mathrm{CT}^{2}$ & 72,68 & 77,83 & & 78,44 & 73,05 \\
$\mathrm{CNF}^{2}$ & 62,51 & 67,73 & & 30,99 & 23,87 \\
FDA $^{2}$ & 3,74 & 4,14 & & 39,48 & 38,41 \\
Lignina $^{2}$ & 1,15 & 1,29 & & 6,69 & 5,91 \\
\hline
\end{tabular}

1 Uréia/Sulfato de amônia (9:1); ${ }^{2} \%$ MS

As amostras de volumoso, concentrado e das sobras de cada animal foram coletadas diariamente. Semanalmente, essas amostras foram pré-secas em estufa com ventilação forçada a $60^{\circ} \mathrm{C}$ e trituradas em moinho de faca (peneira de $1 \mathrm{~mm}$ ). Em seguida, foram feitas amostras compostas de cada quatro semanas (período de 28 dias) com base no peso seco.

As análises laboratoriais foram realizadas de acordo com descrições de Silva \& Queiroz (2002), com exceção das avaliações de FDN e FDA, realizadas conforme métodos descritos por Mertens (2002) e Van Soest \& Robertson (1985), respectivamente. Os carboidratos totais (CT) e os nutrientes digestíveis totais (NDT) foram calculados segundo o método descrito por Sniffen et al. (1992), em que: $\mathrm{CT}=100$ - (\%PB + \%EE + \% Cinzas). O NDT dos alimentos foi calculado segundo equação descrita pelo NRC (2001).

A digestibilidade dos nutrientes foi determinada por meio da coletas de fezes dos animais, durante dois dias alternados, em horários diferentes (12 e 17 h) na penúltima semana do experimento. As amostras de fezes foram présecas, trituradas em moinho de faca (peneira de $1 \mathrm{~mm}$ ), compostas por animal e posteriormente armazenadas para análises. A excreção fecal foi estimada utilizando-se como indicador interno a fibra em detergente neutro indigestível (FDNi), obtida via incubação ruminal, por 144 horas.
No último dia do experimento, após 4 horas do fornecimento da ração aos animais, procedeu-se à coleta de amostras de sangue e de urina spot dos animais. Após a coleta, as amostras de urina foram diluídas em $40 \mathrm{~mL}$ de $\mathrm{H}_{2} \mathrm{SO}_{4} 0,036 \mathrm{~N}$ e congeladas a $-20^{\circ} \mathrm{C}$ para posterior quantificação da excreção de derivados de purinas.

O sangue foi coletado posteriormente à coleta de urina, por punção da veia jugular, utilizando-se kits comerciais a vácuo, com gel acelerador da coagulação. Em seguida, procedeu-se à centrifugação das amostras a $4.000 \mathrm{rpm}$, durante 15 minutos, para separação do soro, que foi congelado posteriormente.

As amostras de urina foram analisadas quanto aos teores de creatinina e uréia, empregando-se kits comerciais. Calculou-se o volume urinário diário pela relação entre a excreção diária de creatinina, adotando-se como referência a equação descrita por Chizzotti (2004): EC (mg/kgPC) = 32,27 - 0,01093*PC, e sua concentração nas amostras spot. Assim, assumiu-se a excreção urinária diária de uréia como o produto entre sua concentração nas amostras spot e o valor estimado de volume urinário. As estimativas foram expressas em g de $\mathrm{N}$ proveniente da uréia, empregando-se o fator de 0,466.

As análises de alantoína e de ácido úrico na urina foram feitas pelo método colorimétrico, conforme descrito por Fujihara et al. (1987), citados por Chen \& Gomes (1992). A excreção total de derivados de purinas foi calculada pela soma das quantidades de alantoína e ácido úrico excretados na urina, expressas em mmol/dia.

As purinas absorvidas ( $\mathrm{X}, \mathrm{mmol} / \mathrm{dia}$ ) foram calculadas a partir da excreção de derivados de purinas (Y, mmol/dia), por meio da equação: $\mathrm{Y}=0,85 \mathrm{X}+0,385 \mathrm{PC}^{0,75}$, em que: 0,85 é a recuperação de purinas absorvidas como derivados de purinas e $0,385 \mathrm{PC}^{0,75}$, a contribuição endógena para a excreção de purinas (Verbic et al., 1990).

A síntese de compostos nitrogenados microbianos no rúmen ( $\mathrm{Y}, \mathrm{gN} / \mathrm{dia})$ foi calculada em relação às purinas absorvidas ( $\mathrm{X}, \mathrm{mmol} / \mathrm{dia}$ ), por meio da equação: $\mathrm{Y}=70 \mathrm{X} \div$ $(0,83 * 0,116 * 1000)$, em que: 70 representa o conteúdo de $\mathrm{N}$ nas purinas ( $\mathrm{mg} \mathrm{N} / \mathrm{mmol}$ ); 0,83 , a digestibilidade das purinas microbianas e 0,116 , a relação N-purina:N total nas bactérias (Chen \& Gomes, 1992). A eficiência microbiana foi expressa em g PB microbiana/kg de NDT ingeridos (g PBmic/kg NDT).

A concentração de $\mathrm{N}$-uréia sérica foi obtida pelo teor de uréia no soro multiplicado por 0,466 , correspondente ao teor de $\mathrm{N}$ na uréia. O balanço dos compostos nitrogenados (BN) foi obtido no período de digestibilidade pela diferença entre o total de $\mathrm{N}$ ingerido e o total de $\mathrm{N}$ excretado nas fezes e na urina. 
Odelineamento experimental foi inteiramente casualizado em esquema fatorial $2 \times 3$, composto de cana-de-açúcar in natura adicionada ou não de $1,0 \%$ de $\mathrm{CaO}$ e três níveis de concentrado (0,0; 0,5 e 1,0\% do PC). Utilizou-se como co-variável o PC inicial dos animais e, para todos os procedimentos, adotou-se o nível de significância de 5\%. As análises estatísticas foram feitas utilizando-se o programa SAS. Nas equações de regressão, a variável V assume o valor zero para a presença de $\mathrm{CaO}$ na cana-deaçúcar e valor 1 para a ausência de CaO. A variável NC refere-se ao nível de concentrado.

\section{Resultados e Discussão}

Com exceção da FDN, o tratamento da cana-de-açúcar com $\mathrm{CaO}$ prejudicou $(\mathrm{P}<0,05)$ o consumo de todos os demais nutrientes (Tabela 3). Esse prejuízo no consumo dos nutrientes ocasionado pelo decréscimo do consumo de MS pelos animais pode ter sido conseqüência da alta temperatura da cana-de-açúcar com $\mathrm{CaO}$ em comparação à cana in natura picada no momento do fornecimento aos animais. De fato, Domingues et al. (2006) observaram acréscimo na temperatura da cana-de-açúcar após a adição de $1 \%$ de hidróxido de cálcio de $0,53^{\circ} \mathrm{C} / \mathrm{h}$. Além disso, o pH mensurado por esses autores 24 horas após o tratamento da cana-de-açúcar $(9,22)$ foi demasiadamente alcalino, o que ter prejudicado a palatabilidade e limitado o consumo do volumoso tratado.
Houve diferença de 21,12\% no consumo de MO (\% PC) entre os animais que receberam a cana-de-açúcar sem $\mathrm{CaO}$, possivelmente em virtude de a adição do $\mathrm{CaO}$ ter aumentado o teor de matéria mineral consumida pelos animais.

O nível de concentrado influenciou o consumo de nutrientes, que aumentou de forma linear $(\mathrm{P}<0,05)$, o que não ocorreu com a FDN, determinada tanto em $\mathrm{kg} / \mathrm{dia}$ quanto em \% PC ( $>>0,05)$. Este aumento no consumo de MS e dos outros nutrientes pode ser atribuído à menor quantidade de FDN proporcionalmente ingerida em relação ao acréscimo do consumo de MS. Assim, o consumo de MS foi limitado pelo enchimento do rúmen, em decorrência do aumento da fibra. Da mesma forma, ao trabalharem com cana-de-açúcar com diferentes relações volumoso:concentrado, Costa et al. (2005a) constataram acréscimo na ingestão dos nutrientes à medida que aumentaram o nível de concentrado da dieta. Além disso, esses autores encontraram efeito quadrático para o consumo de MS (kg/dia) como resultado da adição de concentrado à dieta.

Os aumentos lineares verificados para consumo de PB, EE, CT e CNF podem ser conseqüência do aumento no consumo de MS e da maior concentração desses nutrientes nas dietas com maiores níveis de concentrado, o que refletiu também sobre o consumo de NDT, que aumentou linearmente com o nível de concentrado, possivelmente em virtude da maior ingestão de CNF e de outros nutrientes mais digestíveis, como PB e EE.

Tabela 3 - Consumo de nutrientes em novilhas alimentadas com cana-de-açúcar tratada com CaO e concentrado

\begin{tabular}{|c|c|c|c|c|c|c|c|c|c|c|}
\hline \multirow[t]{3}{*}{ Item } & \multicolumn{2}{|c|}{ Cana-de-açúcar } & \multicolumn{3}{|c|}{ Nível de concentrado, NC (\% PC) } & \multicolumn{4}{|c|}{ Efeito ${ }^{1}$} & \multirow{3}{*}{$\mathrm{CV}(\%)$} \\
\hline & \multirow[b]{2}{*}{$\mathrm{Com} \mathrm{CaO}^{2}$} & \multirow[b]{2}{*}{ Sem $\mathrm{CaO}^{3}$} & \multirow[b]{2}{*}{0,0} & \multirow[b]{2}{*}{0,5} & \multirow[b]{2}{*}{1,0} & \multirow[t]{2}{*}{$\mathrm{CaO}$} & \multicolumn{2}{|c|}{ NC } & \multirow[t]{2}{*}{$\mathrm{V}: \mathrm{NC}$} & \\
\hline & & & & & & & $\mathrm{L}$ & $\mathrm{Q}$ & & \\
\hline & & & $\mathrm{kg} / \mathrm{dia}$ & & & & & & & \\
\hline $\mathrm{MS}^{4}$ & 3,30 & 3,90 & 2,80 & 3,70 & 4,40 & * & * & ns & ns & 13,8 \\
\hline $\mathrm{MO}^{5}$ & 2,98 & 3,74 & 2,59 & 3,41 & 4,09 & * & * & ns & ns & 14,3 \\
\hline FDN & 1,30 & 1,46 & 1,33 & 1,39 & 1,42 & ns & ns & ns & ns & 16,3 \\
\hline $\mathrm{CT}^{8}$ & 2,88 & 3,57 & 2,50 & 3,31 & 3,85 & $*$ & $*$ & ns & ns & 11,8 \\
\hline $\mathrm{CNF}^{9}$ & 1,27 & 1,75 & 0,91 & 1,51 & 2,10 & * & * & ns & ns & 14,3 \\
\hline \multirow[t]{2}{*}{$\mathrm{NDT}^{10}$} & 2,86 & 3,78 & 2,53 & 3,40 & 4,01 & $*$ & $*$ & ns & ns & 14,3 \\
\hline & & & $\%$ PC & & & & & & & \\
\hline
\end{tabular}

${ }^{1}$ Nas equações de regressão, a variável $\mathrm{V}$ assume o valor 0 para a presença de $\mathrm{CaO}$ na cana-de-açúcar e 1 na ausência de CaO. L e Q referem-se respectivamente, a efeito linar e quadrático do NC; * e ns referem-se, respectivamente, a efeitos significativo e não-significativo a $5 \%$.

${ }^{2} \mathrm{Com} \mathrm{CaO} ;{ }^{3} \mathrm{Sem} \mathrm{CaO} ;{ }^{4} \hat{\mathrm{Y}}=2,6098+0,6258 \mathrm{~V}+1,4187 \mathrm{NC}\left(\mathrm{r}^{2}=0,73\right) ;{ }^{5} \hat{\mathrm{Y}}=2,3408+0,7241 \mathrm{~V}+1,3200 \mathrm{NC}\left(\mathrm{r}^{2}=0,76\right) ;{ }^{6} \hat{\mathrm{Y}}=0,4254+0,1042 \mathrm{~V}+0,2075 \mathrm{NC}$ $\left(r^{2}=0,79\right) ;{ }^{7} \hat{Y}=0,01082+0,01558 \mathrm{~V}+0,2640 N C\left(r^{2}=0,84\right) ;{ }^{8} \hat{Y}=2,2798+0,6667 V+1,2187\left(r^{2}=0,80\right) ;{ }^{9} \hat{Y}=0,7104+0,4750 V+1,1225 N C\left(r^{2}=0,89\right) ;$ $10 \hat{\mathrm{Y}}=2,1971+0,8958 \mathrm{~V}+1,3475 \mathrm{NC}\left(\mathrm{r}^{2}=0,82\right) ;{ }^{11} \hat{\mathrm{Y}}=1,4381+0,2442 \mathrm{~V}+0,5738 \mathrm{NC}\left(\mathrm{r}^{2}=0,87\right) ; 12 \hat{\mathrm{Y}}=1,2960+0,2967 \mathrm{~V}+0,5312 \mathrm{NC}\left(\mathrm{r}^{2}=0,89\right)$. 
Não houve efeito do tratamento da cana-de-açúcar com $1 \%$ de $\mathrm{CaO}$ sobre as digestibilidades dos nutrientes $(\mathrm{P}>0,05)$, logo, o tratamento não foi eficiente na melhoria da digestibilidade da cana (Tabela 4), o que contraria o princípio da hidrólise, que se baseia no fenômeno conhecido como "intumescimento alcalino da celulose", que consiste na expansão e ruptura das moléculas de celulose (Jackson, 1977), o que melhoraria o aproveitamento do alimento pelos microrganismos ruminais.

Silva et al. (2006a,b) verificaram comportamento inverso, pois constataram aumento na digestibilidade in vitro da MS da cana-de-açúcar submetida ao mesmo tratamento com CaO. Do mesmo modo, Oliveira et al. (2006) relataram que o tratamento com $0,5 \%$ de $\mathrm{CaO}$ melhorou a digestibilidade in vitro da MS e da FDN. Embora os valores absolutos da digestibilidade in vitro e in vivo não devam ser comparados, os resultados relativos podem servir como parâmetro na comparação de comportamento da variável.

O aumento do nível de concentrado influenciou de forma linear crescente as digestibilidades da MS e MO $(\mathrm{P}<0,05)$, provavelmente em virtude do aumento na ingestão de CNF, uma vez que sua digestibilidade é maior que da FDN. A ingestão de NDT aumentou linearmente de acordo com o nível de concentrado das dietas, pois a adição de concentrado às rações contribui positivamente para a digestibilidade dos nutrientes. Do mesmo modo, Costa et al. (2005a) encontraram efeito linear positivo quando avaliaram o efeito do nível de concentrado na dieta sobre as digestibilidades da MS e da MO. Ladeira et al. (1999), no entanto, encontraram efeito quadrático da inclusão de concentrado na dieta sobre as digestibilidades aparentes totais da MS e MO.

Observou-se ainda efeito linear decrescente $(\mathrm{P}<0,05)$ do nível de concentrado na digestibilidade da PB e efeito linear crescente $(\mathrm{P}<0,05)$ sobre a digestibilidade do $\mathrm{EE}$. A redução na digestibilidade aparente da $\mathrm{PB}$ pode ter sido decorrente da melhor utilização ruminal da uréia. Costa et al. (2005a) observaram efeito linear crescente do nível de concentrado sobre a digestibilidade da PB e do EE. Ladeira et al. (1999), no entanto, encontraram efeito linear crescente sobre a digestibilidade da PB e efeito quadrático sobre a digestibilidade do EE. Costa et al. (2005b) não observaram aumento na digestibilidade da PB e efeito linear crescente na digestibilidade do EE com o aumento do nível de concentrado em dietas contendo cana-deaçúcar como volumoso.

Não houve efeito do nível de concentrado na digestibilidade da FDN (P>0,05). Costa et al. (2005b) verificaram o mesmo comportamento em dietas contendo canade-açúcar. Bürger et al. (2000) e Silva et al. (2005) também não encontraram efeito do nível de concentrado sobre a digestibilidade da FDN.

Efeito quadrático do nível de concentrado sobre a digestibilidade total da FDN foi observado por Ladeira et al. (1999) e Dias et al. (2000a). Tibo et al. (2000), no entanto, observaram efeito linear decrescente na digestibilidade da FDN de acordo com o aumento do nível de concentrado na dieta. Neste estudo, observou-se efeito linear crescente $(\mathrm{P}<0,05)$ do nível de concentrado sobre a digestibilidade dos carboidratos totais, o que pode ser explicado pelo aumento na proporção de CNF nas dietas com maior quantidade de concentrado. Esse comportamento também foi observado por Dias et al. (2000a) e Silva et al. (2005), ao passo que Costa et al. (2005a) não observaram efeito do nível de concentrado em dietas com cana-de-açúcar como volumoso.

A cana-de-açúcar com $\mathrm{CaO}$ afetou negativamente $(\mathrm{P}<0,05)$ a ingestão de $\mathrm{N}$ e o balanço de $\mathrm{N}$ (Tabela 5), mesmo comportamento observado para o consumo de PB (Tabela 3). Apenas a eficiência microbiana por kg de NDT consumido (ENDT) e o nitrogênio uréico na urina (NU) não foram afetados $(\mathrm{P}>0,05)$ pelo aumento do nível de concentrado

Tabela 4 - Digestibilidade total de nutrientes em novilhas alimentadas com cana-de-açúcar tratada com CaO

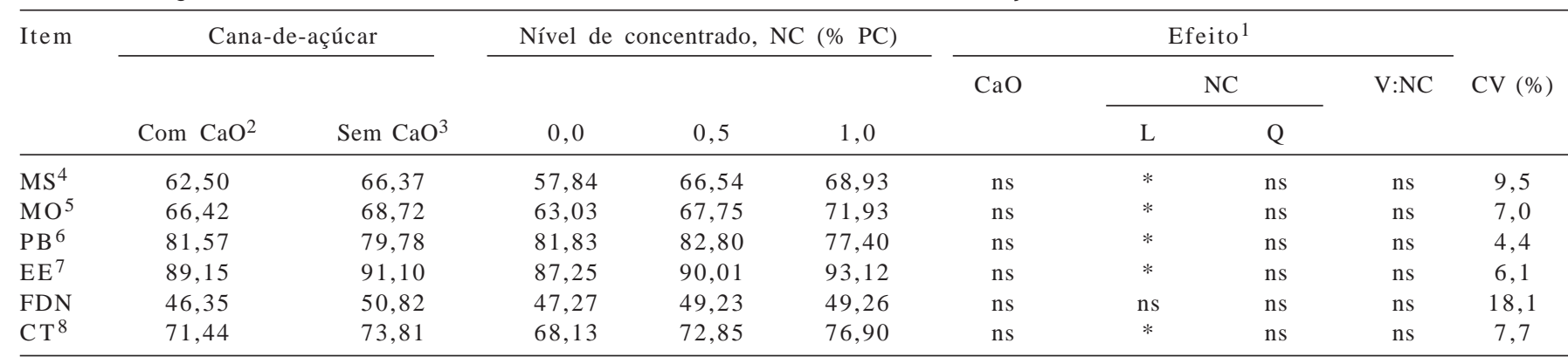

${ }^{1}$ Nas equações de regressão, a variável V assume o valor 0 para a presença de CaO na cana-de-açúcar e valor 1 na ausência de CaO. L e Q referem-se respectivamente, aos efeitos linear e quadrático do nível de concentrado. * e ns referem-se, respectivamente, aos efeitos significativo e não-significativo a $5 \%$.

${ }^{2} \mathrm{Com} \mathrm{CaO} ;{ }^{3} \mathrm{Sem} \mathrm{CaO} ;{ }^{4} \hat{\mathrm{Y}}=58,6376+3,8642 \mathrm{NC}\left(\mathrm{r}^{2}=0,72\right) ;{ }^{5} \hat{\mathrm{Y}}=63,0100+8,8912 \mathrm{NC}\left(\mathrm{r}^{2}=0,70\right) ;{ }^{6} \hat{\mathrm{Y}}=82,8492-4,4288 \mathrm{NC}\left(\mathrm{r}^{2}=0,50\right) ;{ }^{7} \hat{\mathrm{Y}}=86,9991$ $+5,8775 \mathrm{NC}\left(\mathrm{r}^{2}=0,73\right) ;{ }^{9} \hat{\mathrm{Y}}=68,2927+8,7675 \mathrm{NC}\left(\mathrm{r}^{2}=0,82\right)$. 
na dieta. A síntese de proteína microbiana depende da disponibilidade de carboidratos e de nitrogênio no rúmen (NRC, 2001). Assim, o crescimento microbiano é maximizado pela sincronização entre a disponibilidade da energia fermentável e o $\mathrm{N}$ degradável no rúmen (Dewhurst et al., 2000).

Os valores encontrados para ENDT estiveram pouco abaixo do valor de $130 \mathrm{~g}$ PBmic/kg NDT preconizado pelo NRC (2001). No entanto, foram bem próximos ao valor de $120 \mathrm{~g}$ PBmic/kg NDT recomendado por Valadares Filho et al. (2006) para condições tropicais. A síntese microbiana (Nmic) aumentou de forma linear $(\mathrm{P}<0,05)$ com o aumento do nível de concentrado nas dietas.

Ítavo et al. (2002) e Dias et al. (2000b) não observaram efeito do nível de concentrado sobre o Nmic. Resultado similar foi observado por Barbosa et al. (2006) ao avaliarem dietas com dois níveis de concentrado (25 e 50\%). Rennó et al. (2000), no entanto, observaram efeito de nível de concentrado sobre o Nmic em animais mestiços Holandês $\times$ Zebu. Considerando os resultados descritos por esses autores e os deste estudo, constata-se que os efeitos do nível de concentrado sobre o Nmic são variáveis.

De fato, segundo Firkins et al. (1998), o fluxo de Nmic pode ser influenciado, além do nível de concentrado, pelo percentual de FDN, que afeta o $\mathrm{pH}$ ruminal, ou pelo suprimento de proteína degradável no rúmen.

Nesta pesquisa, as variáveis Nmic, NS, NI e NF aumentaram $(\mathrm{P}<0,05)$ com os níveis de concentrado nas dietas. Existe correlação positiva entre ingestão de $N$ e concentração de uréia no plasma (Preston et al., 1965). Segundo Valadares et al. (1999), as concentrações de nitrogênio no plasma (NP) e NU estão relacionadas e valores entre 14,0 e 16,0 mg/dL de NP representariam limites a partir dos quais ocorreriam perdas de proteína dietética. No entanto, apesar de o NS ter sido afetado pelos níveis de concentrado, não foi observado efeito sobre o nitrogênio uréico na urina.

Segundo Magalhães et al. (2005), não foi relatada ainda concentração plasmática de uréia a partir da qual se pudesse confirmar a perda de proteína, a utilização ineficiente de nitrogênio ou a condição nutricional inadequada.

O balanço de nitrogênio foi maior $(\mathrm{P}<0,05)$ nos animais que consumiram cana-de-açúcar sem $\mathrm{CaO}$ e aumentou de acordo com o nível de concentrado na dieta. Ressalta-se que, independentemente das dietas avaliadas, não foi verificado balanço de nitrogênio negativo, logo, o consumo de $\mathrm{PB}$ atendeu às exigências protéicas dos animais. De forma contrária, Dias et al. (2000b) verificaram BN negativo para os tratamentos com 25 e 37,5\% de concentrado. Segundo esses autores, além do não atendimento das exigências protéicas dos animais, desbalanços de energia e proteína nas dietas podem ter ocorrido e possivelmente resultaram em mobilização de tecidos corporais.

O comportamento linear positivo $(\mathrm{P}<0,05)$ para o balanço de nitrogênio em relação ao nível de concentrado pode ser explicado pelo maior aporte de nitrogênio, que resultou em maior retenção de nitrogênio no organismo do animal (Dias et al., 2000b).

Tanto o GMD quanto o PCF foram menores $(\mathrm{P}<0,05)$ nos animais alimentados com cana-de-açúcar tratada com CaO (Tabela 6). Além disso, o GMD e o PCF nos animais alimentados com cana-de-açúcar sem $\mathrm{CaO}$ foram 42,2 e $5 \%$ superiores aos das novilhas alimentadas com cana-de-açúcar com $\mathrm{CaO}$, respectivamente. Avaliando os níveis de concentrado, verificou-se comportamento

Tabela 5 - Compostos nitrogenados microbianos (Nmic), eficiência microbiana por kg de NDT consumido (ENDT), nitrogênio uréico no soro (NS), ingerido (NI), na urina (NU) e nas fezes (NF) e balanço de nitrogênio (BN) em novilhas alimentadas com cana-deaçúcar tratada com $\mathrm{CaO}$ e concentrado

\begin{tabular}{|c|c|c|c|c|c|c|c|c|c|c|}
\hline \multirow[t]{2}{*}{ Item } & \multicolumn{2}{|c|}{ Cana-de-açúcar } & \multicolumn{3}{|c|}{ Nível de concentrado, NC (\% PC) } & \multicolumn{4}{|c|}{ Efeito $^{1}$} & \multirow{2}{*}{ CV (\%) } \\
\hline & $\mathrm{Com} \mathrm{CaO}^{2}$ & Sem $\mathrm{CaO}^{3}$ & 0,0 & 0,5 & 1,0 & $\mathrm{CaO}$ & $\mathrm{L}$ & $\mathrm{Q}$ & $\mathrm{V}: \mathrm{NC}$ & \\
\hline $\mathrm{Nmic}^{2}$ & 42,99 & 57,91 & 36,36 & 53,57 & 61,43 & ns & $*$ & ns & ns & 33,5 \\
\hline ENDT & 120,1 & 120,1 & 120,2 & 120,2 & 111,0 & ns & ns & ns & ns & 8,6 \\
\hline $\mathrm{NS}^{4}$ & 15,49 & 17,02 & 12,03 & 17,72 & 19,09 & ns & $*$ & ns & ns & 13,4 \\
\hline $\mathrm{NI}^{5}$ & 104,0 & 118,7 & 84,7 & 123,0 & 126,4 & $*$ & $*$ & ns & ns & 13,4 \\
\hline $\mathrm{BN}^{7}$ & 42,48 & 52,15 & 26,74 & 49,14 & 55,04 & $*$ & $*$ & ns & ns & 13,2 \\
\hline
\end{tabular}

${ }^{1}$ Nas equações de regressão a variável $V$ assumirá o valor 0 para a presença de CaO na cana-de-açúcar, e valor 1 na ausência de CaO; L e Q referem-se, respectivamente, efeito linar e quadrático do nível de concentrado; * e ns referem-se, respectivamente, a efeitos significativo e não-significativo a $5 \%$.

${ }^{2} \mathrm{Com} \mathrm{CaO} ;{ }^{3} \mathrm{Sem} \mathrm{CaO} ;{ }^{2} \hat{\mathrm{Y}}=37,4056+25,06622 \mathrm{C}\left(\mathrm{r}^{2}=0,63\right) ;{ }^{3} \hat{\mathrm{Y}}=467,5582+313,3462 \mathrm{NC}\left(\mathrm{r}^{2}=0,63\right) ;{ }^{4} \hat{\mathrm{Y}}=12,5395+7,1863 \mathrm{NC}\left(\mathrm{r}^{2}=0,90\right) ;{ }^{5} \hat{\mathrm{Y}}=67,8091$ $+16,6217 \mathrm{~V}+0,0387 \mathrm{NC}\left(\mathrm{r}^{2}=0,75\right)^{6} \hat{\mathrm{Y}}=15,2797+10,6562 \mathrm{NC}\left(\mathrm{r}^{2}=0,89\right) ;{ }^{7} \hat{\mathrm{Y}}=39,4333+9,3212 \mathrm{~V}+8,0000 \mathrm{NC}\left(\mathrm{r}^{2}=0,86\right)$ 
Tabela 6 - Ganho médio diário (GMD - g/dia) e peso vivo final (PVF - kg) em novilhas alimentadas com cana-de-açúcar tratada com CaO e concentrado

\begin{tabular}{|c|c|c|c|c|c|c|c|c|c|c|}
\hline \multirow[t]{2}{*}{ Item } & \multicolumn{2}{|c|}{ Cana-de-açúcar } & \multicolumn{3}{|c|}{ Nível de concentrado, NC (\% PC) } & \multicolumn{4}{|c|}{ Efeito ${ }^{1}$} & \multirow{2}{*}{ CV (\%) } \\
\hline & $\mathrm{Com} \mathrm{CaO}^{2}$ & Sem $\mathrm{CaO}^{3}$ & 0,0 & 0,5 & 1,0 & $\mathrm{CaO}$ & $\mathrm{L}$ & $\mathrm{Q}$ & $\mathrm{V}: \mathrm{NC}$ & \\
\hline $\mathrm{GMD}^{2}$ & 308,05 & 438,98 & 164,7 & 390,1 & 565,6 & * & $*$ & ns & ns & 28,8 \\
\hline $\mathrm{PVF}^{3}$ & 202,54 & 213,54 & 190,5 & 209,4 & 224,2 & * & $*$ & ns & ns & 4,3 \\
\hline
\end{tabular}

${ }^{1}$ Nas equações de regressão a variável V assumirá o valor 0 para a presença de CaO na cana-de-açúcar, e valor 1 na ausência de CaO. L e Q referem-se respectivamente, efeito linar e quadrático da OC. * e ns referem-se, respectivamente, significativo e não-significativo a $5 \%$; ${ }^{2} \mathrm{Com}$ CaO; ${ }^{3}$ Sem $\mathrm{CaO}$;

$2 \hat{\mathrm{Y}}=114,8319+128,9683 \mathrm{~V}+388,3912 \mathrm{NC}\left(\mathrm{r}^{2}=0,81\right) ;{ }^{3} \hat{\mathrm{Y}}=190,6146+9,6667 \mathrm{~V}+25,1875 \mathrm{NC}\left(\mathrm{r}^{2}=0,87\right)$

linear positivo do GMD e PCF com a adição de concentrado às dietas.

O desempenho animal é determinado por vários fatores, sobretudo pelo consumo, que determina o nível de ingestão de nutrientes. Segundo Rohr \& Daenicke (1984), o GMD é uma medida indispensável para se estimar o desenvolvimento do animal nos processos alimentares e sistemas de produção.

Ressalta-se que o consumo de MS (\% PC) entre os animais alimentados com cana-de-açúcar tratada com $\mathrm{CaO}$ foi $15,3 \%$ inferior ao daqueles que receberam a cana-deaçúcar in natura sem adição de $\mathrm{CaO}$ (Tabela 3). Esses animais tiveram melhor balanço de nitrogênio, portanto, houve retenção de proteína no organismo animal, proporcionando condições favoráveis para melhores ganhos de peso.

A velocidade de crescimento também foi conseqüência da maior quantidade de energia ingerida (Bond et al., 1972) e da maior digestibilidade dos nutrientes pelos animais que se alimentaram com dietas contendo maior proporção de concentrado.

Considerando a importância da fermentação microbiana na digestão em ruminantes, é importante a avaliação do nitrogênio disponível para a absorção pelo animal (Valadares et al., 1997). De acordo com Silva \& Leão (1979), o balanço de nitrogênio é um método de avaliação dos alimentos e do estado nutricional do corpo do animal e consiste em determinar a ingestão de nitrogênio e todas as suas perdas pelo corpo, inclusive na pele e nos pêlos. Neste contexto, os animais que ganharam mais peso tiveram maior balanço de nitrogênio.

Costa et al. (2005b), trabalhando com diferentes porcentagens de concentrado em dietas com cana-deaçúcar, encontraram o mesmo comportamento para GMD. Do mesmo modo, Costa et al. (2005a) e Resende et al. (2001) verificaram efeito linear crescente do aumento da oferta de concentrado sobre o desempenho dos animais.

\section{Conclusões}

A cana-de-açúcar com a adição de $1 \%$ de $\mathrm{CaO}$ fornecida após 24 horas de armazenamento não altera a digestibilidade, mas prejudica o consumo de nutrientes, o balanço de compostos nitrogenados e o desempenho animal. A inclusão de concentrado em até $1,0 \%$ PC na dieta melhora a ingestão e a digestibilidade da maioria dos nutrientes, resultando em melhor desempenho animal. Não há evidências para se recomendar a adição do óxido de cálcio à canade-açúcar.

\section{Literatura Citada}

BARBOSA, A.M.; VALADARES, R.F.D.; VALADARES FILHO, S.C. et al. Efeito do período de coleta de urina, do concentrado e de fontes protéicas sobre a excreção de creatinina, de uréia e de derivados de purina e a produção microbiana em bovinos Nelore Revista Brasileira de Zootecnia, v.35, n.3, p.870-877, 2006. BERGER, L.L.; FAHEY, G.C; BOURQUIN, L.D. et al. Modification of forage after harvest. In: FAHEY, D.C. (Ed.) Forage quality, evaluation, and utilization. 1.ed. Madison: American Society of Agronomy, Crop Science Society, Soil Science Society, 1994. p.922-966.

BOND, J.; HOOVEN, J.R.N.W.; WARICK, E. et al. Influence of breed and plane of nutrition on performance of dairy, dualpurpose and beef steers. II. From 180 days of age to slaughter. Journal of Animal Science, v.34, n.6, p.1046-1053, 1972.

BÜRGER, P.J.; PEREIRA, J.C; SILVA, J.F.C. et al. Consumo e digestibilidade aparente total e parcial em bezerros holandeses alimentados com dietas contendo diferentes concentrado. Revista Brasileira de Zootecnia, v.29, n.1, p.206-214, 2000 (supl.).

CHIZZOTTI, M.L. Avaliação da casca de algodão para novilhos de origem leiteira e determinação da excreção de creatinina e produção de proteína microbiana em novilhas e vacas leiteiras. Viçosa, MG: Universidade Federal de Viçosa, 2004. 132p. Dissertação (Mestrado em Zootecnia) - Universidade Federal de Viçosa, 2004.

CHEN, X.B.; GOMES, M.J. Estimation of microbial protein supply to sheep and cattle based on urinary excretion of purine derivatives-an overview of the technical details. Buchsburnd: Rowett Research Institute, 1992. 21p. (Occasional publication).

COSTA, M.A.L.; VALADARES FILHO, S.C.; PAULINO, M.F. et al. Desempenho, digestibilidade e características de carcaça de 
novilhos zebuínos alimentados com dietas contendo diferentes concentrados. Revista Brasileira de Zootecnia, v.34, n.1, p.268-279, 2005a.

COSTA, M.G.; CAMPOS, J.M.S., VALADARES FILHO, S.C. Desempenho produtivo de vacas leiteiras alimentadas com diferentes proporções de cana-de-açúcar e concentrado ou silagem de milho na dieta. Revista Brasileira de Zootecnia, v.34, n.6, p.2437-2445, 2005b (supl.).

DEWHURST, R.J.; DAVIES, D.R.; MERRY, R.J. Microbial protein supply from the rumen. Animal Feed Science and Technology, v.85, p.1-21, 2000.

DIAS, H.L.C.; VALADARES FILHO, S.C.; SILVA, J.F.C. et al. Consumo e digestões totais e parciais em novilhos $\mathrm{F}_{1}$ Limousin $\mathrm{x}$ nelore alimentados com dietas contendo cinco concentrado. Revista Brasileira de Zootecnia, v.29, n.2, p.545-554, 2000a.

DIAS, H.L.C.; VALADARES FILHO, S.C.; SILVA, J.F.C. et al. Eficiência de síntese microbiana, $\mathrm{pH}$ e concentrações ruminais de amônia em novilhos $\mathrm{F}_{1}$ Limousin $\mathrm{x}$ Nelore alimentados com dietas contendo cinco concentrado. Revista Brasileira de Zootecnia, v.29, n.2, p.555-563, 2000b.

DOMINGUES, F.N.; OLIVEIRA, M.D.S, SIQUEIRA, G.R. et al. Efeito das doses de cal $(\mathrm{CaO})$ microprocessada e do tempo após o tratamento sobre a estabilidade aeróbia e dinâmica de microrganismos da cana-de-açúcar in natura. In: REUNIÃO ANUAL DA SOCIEDADE BRASILEIRA DE ZOOTECNIA, 43., 2006, João Pessoa. Anais... João Pessoa: Sociedade Brasileira de Zootecnia, 2006. (CD-ROM).

EZEQUIEL, J.M.B.; QUEIROZ, M.A.A.; GALATI, R.L. et al. Processamento da cana-de-açúcar: Efeito sobre a digestibilidade, o consumo e a taxa de passagem. Revista Brasileira de Zootecnia, v.34, n.5, p.1704-1710, 2005.

FIRKINS, J.L.; ALLEN, M.S.; OLDICK, B.S. et al. Modeling ruminal digestibility of carbohydrates and microbial protein flow to the duodenum. Journal of Dairy Science, v.81, n.12, p.33503369, 1998.

ÍTAVO, L.C.V.; VALADARES FILHO, S.C.; SILVA, F.F. et al. Produção microbiana e parâmetros ruminais de novilhos alimentados com dietas contendo vários concentrado. Revista Brasileira de Zootecnia, v.31, n.3, p.1553-1561, 2002.

JACKSON, M.G. The alkali treatments of straws. Animal Feed Science and Technology, v.2, n.2, p.105-130, 1977.

LADEIRA, M.M.; VALADARES FILHO, S.C.; SILVA, J.F.C. et al. Consumo e digestibilidades aparentes totais e parciais de dietas contendo diferentes concentrado, em novilhos nelore. Revista Brasileira de Zootecnia, v.28, n.2, p.395-403, 1999.

MAGALHÃES, K.A.; VALADARES FILHO, S.C.; VALADARES, R.F.D. et al. Produção de proteína microbiana, concentração plasmática de uréia e excreções de uréia em novilhos alimentados com diferentes níveis de uréia ou casca de algodão. Revista Brasileira de Zootecnia, v.34, n.4, p.1400-1407, 2005.

MENDONÇA, S.S.; CAMPOS, J.M.S.; VALADARES FILHO, S.C. et al. Consumo, digestibilidade aparente, produção e composição do leite e variáveis ruminais em vacas leiteiras alimentadas com dietas à base de cana-de-açúcar. Revista Brasileira de Zootecnia, v.33, n.2, p.481-492, 2004.

MERTENS, D.R. Gravimetric determination of amylase treated neutral detergent fiber in feeds with refluxing in beakers or crucibles: collaborative study. Journal of AOAC International, v.85, n.6, p.1212-1240, 2002.

NATIONAL RESEARCH COUNCIL - NRC. Nutrient requirements of dairy cattle. 7.ed. Washinton, D.C.: National Academic Press, 2001. 381p.

OLIVEIRA, M.D.S, SHINODA, J.; BODRIK R. et al. Efeito da hidrólise da cal hidratada (hidróxido de cálcio) sobre a digestibilidade in vitro da cana-de-açúcar (Saccharum officinarum). In: REUNIÃO ANUAL DA SOCIEDADE BRASILEIRA DE ZOOTECNIA, 43., 2006, João Pessoa. Anais... João Pessoa: Sociedade Brasileira de Zootecnia, 2006. (CD-ROM).
PRESTON, R.L.; SCHNAKENBERG, D.D.; PFANDER, W.H. Protein utilization in ruminants. I. Blood urea nitrogen as affected by protein intake. Journal of Nutrition, v.68, p.281288, 1965.

RENNÓ, L.N.; VALADARES, R.F.D.; VALADARES FILHO, S.C. et al. Estimativa da produção de proteína microbiana pelos derivados de purinas na urina em novilhos. Revista Brasileira de Zootecnia, v.29, n.4, p.1223-1234, 2000

RESENDE, F.D.; QUEIROZ, A.C.; OLIVEIRA, J.V. et al. Bovinos mestiços alimentados com diferentes proporções de volumoso:concentrado. 1. Digestibilidade aparente dos nutrientes, ganho de peso e conversão alimentar. Revista Brasileira de Zootecnia, v.30, n.1, p.261-269, 2001.

ROHR, K.; DAENICKE, R. Nutritional effects on the distribution of live weight as gastrointestinal tract fill and tissue components in growing cattle. Journal of Animal Science, v.58, n.3, p.753-795, 1984.

SANTOS, M.C.; NUSSIO, L.G.; SOUSA, D.P. et al. Estabilidade aeróbia e perda de matéria seca de cana-de-açúcar in natura tratada com níveis crescentes de óxido de cálcio. In: REUNIÃO ANUAL DA SOCIEDADE BRASILEIRA DE ZOOTECNIA, 42. 2005, Goiânia. Anais... Goiânia: Sociedade Brasileira de Zootecnia, 2005. (CD-ROM).

SILVA, C.J.F.; LEÃO, M.I. Fundamentos da nutrição de ruminantes. Piracicaba: Livroceres, 1979. 384p

SILVA, D.J.; QUEIROZ, A.C. Análise de alimentos: métodos químicos e biológicos. 3.ed. Viçosa, MG: Editora UFV, 2002. 165p.

SILVA, F.F.; VALADARES FILHO, S.C.; ÍTAVO, L.C.V. et al. Consumo, desempenho, e características de carcaça e biometria do trato gastrintestinal e dos órgãos internos de novilhos nelore recebendo dietas com diferentes concentrados e proteína. Revista Brasileira de Zootecnia, v.34, n.1, p.268-279, 2005.

SILVA, T.M.; OLIVEIRA, M.D.S.; SAMPAIO, A.A.M. et al. Efeito da hidrólise de diferentes variedades de cana-de-açúcar sobre a digestibilidade ruminal in vitro. In: REUNIÃO ANUAL DA SOCIEDADE BRASILEIRA DE ZOOTECNIA, 43., 2006, João Pessoa. Anais... João Pessoa: Sociedade Brasileira de Zootecnia, 2006a. (CD-ROM).

SILVA, R.A.; CACERE, E.R.; DIAS, A.C.S. et al. Efeito da adição da cal hidratada na cana-de-açúcar picada sobre a composição química e digestibilidade in vitro da matéria seca. In: REUNIÃO ANUAL DA SOCIEDADE BRASILEIRA DE ZOOTECNIA, 43, 2006, João Pessoa. Anais... João Pessoa: Sociedade Brasileira de Zootecnia, 2006b. (CD-ROM).

SNIFFEN, C.J.; O’CONNOR, J.D; Van SOEST, P.J. et al. A net carbohydrate and protein system for evaluating cattle diets. II. Carbohydrate and protein availability. Journal of Animal Science, v.70, n.11, p.3562-3577, 1992.

TIBO, G.C.; VALADARES FILHO, S.C.; VALADARES, R.F.D. et al. Concentrado em dietas de novilhos mestiços $\mathrm{F} 1$ simental $\mathrm{x}$ nelore. 1. consumo e digestibilidades. Revista Brasileira de Zootecnia, v.29, n.3, p.910-920, 2000.

VALADARES, R.F.D.; GONÇALVES, L.C.; SAMPAIO, I.B. et al. Níveis de proteína em dietas de bovinos. 4. Concentrações de uréia plasmática e excreções de uréia e creatinina. Revista Brasileira de Zootecnia, v.26, n.6, p.1270-1278, 1997.

VALADARES FILHO, S.C.; AZEVÊDO, J.A.G.; PINA, D.S. et al. Consumo de matéria seca de bovinos nelore e mestiços. In: VALADARES FILHO, S.C.; PAULINO, P.V.R; MAGALHÃES, K.A. (Eds.) Exigências nutricionais de zebuínos e tabelas de composição de alimentos BR-Corte. 1.ed. Viçosa, MG: Universidade Federal de Viçosa, 2006. 142p.

Van SOEST, P.J.; ROBERTSON, J.B. Analysis of forages and fibrous foods. Ithaca: Cornell University, 1985. 202p.

VERBIC, J.; CHEN, X.B.; MACLEOD, N.A. et al. Excretion of purine derivatives by ruminants. Effect of microbial nucleic acid infusion on purine derivative excretion by steers. Journal of Agricultural Science, v.114, n.3, p.243-248, 1990. 